\title{
Production of Smokeless Briquette Fuel from Sub-bituminous Coal for Domestic and Industrial Uses
}

\author{
Izuchukwu Francis Okafor*, Cosmas Ngozichukwu Anyanwu \\ National Centre for Energy Research and Development, University of Nigeria Nsukka, Enugu State, Nigeria
}

Email address:

izuchukwu.okafor@unn.edu.ng

\section{To cite this article:}

Izuchukwu Francis Okafor, Cosmas Ngozichukwu Anyanwu. Production of Smokeless Briquette Fuel from Sub-bituminous Coal for Domestic and Industrial Uses. Science Journal of Energy Engineering. Vol. 3, No. 4, 2015, pp. 33-39. doi: 10.11648/j.sjee.20150304.11

\begin{abstract}
This study highlighted on coal production and reserves in Nigeria, chemical characteristics of air dried coal and utilization potential of the Nigerian coal in the domestic and industrial sectors. It discussed coal briquetting technology and processes involved in producing smokeless briquette fuel - coal drying, screening, crushing and carbonization to remove obnoxious volatile matters. The coal briquetting press developed at Energy Research Center University of Nigeria, Nsukka was used to produce three different briquette samples (B), (C) and (D) using a sub-bituminous coal obtained from Onyeama Mine in Enugu. The coal sample was pulverized, sieved and carbonized at the temperature of about $550^{\circ} \mathrm{C}$, and mixed with $5 \%, 10 \%$ and $15 \%$ starch-binder concentrations respectively and compacted under pressure of $9 \mathrm{~N} / \mathrm{mm}^{2}$ and allowed to stay for five minutes before ejection. The briquette $\mathrm{D}$ possessed better handling quality than briquette $\mathrm{B}$ and $\mathrm{C}$, but has lower calorific value, higher ignition time and lower burning rate. The moisture contents and volatiles of the briquettes tend to increase with increase in starch-binder concentrations, while the ash content decreased with an increase in starch-binder concentration. The calorific values and fixed carbon content of the produced briquettes decreased with an increase in the starch-binder concentrations and this could be due to decrease in the coal content of the briquettes, which has a higher calorific value and fixed carbon.
\end{abstract}

Keywords: Coal, Briquetting Processes, Coal Briquettes, Starch-Binder

\section{Introduction}

Like other parts of the world, coal was the oldest commercial fuel to be exploited by Nigeria [1]. Coal mining in Nigeria began in 1916. Average production in the first decade was $>150,000$ tons annually. This reached around 300,000 tons/year by the time World War II broke out. From 1940s to mid-1960s, production averaged $>600,000$ tons a year, until the Nigerian civil war (1967-70) disrupted the mining activities [2]. Coal production in Nigeria reached the peak in 1950s [3]. In 1976/77, production began to decline rapidly, reaching as low as 53,500 tons annually in 1983. Figure 1 shows the coal production in Nigeria for the period of 1980 to 2012 [4]. The decline was attributed to the advent of the "oil boom" and the shift of attention from coal. The "dieselization" undertaken by the Nigerian Railway Corporation (NRC) (major customer of the coal industry), switching to natural gas and oil by several Power Stations; another major consumer of coal in Nigeria and the disruptive consequences of the civil war also led to the decline in coal consumption in Nigeria [2]. Table 1 shows the coal reserves and coal fields in Nigeria, indicating great potential and Table 2 shows the chemical characteristics of the air dried Nigerian sub-bituminous and lignite coals.

Despite the abundance of coal resources in Nigeria, it still remains the smallest contributor to the overall fuel energy mix in the country. In 2001 , coal accounted for only about $0.2 \%$ of Nigeria energy consumption [5]. However, efforts are currently being made by Nigerian Government to increase the country's level of coal utilization to help reduce over dependence on crude oil and to stem the loss of forests to domestic fuelwood harvesting. With about 100 million $\mathrm{m}^{3}$ of wood consumed annually, Nigeria's forests are under severe pressure from harvesting fuelwood for cooking [6]. The environmental consequences of deforestation- the erosion of watersheds, flooding, destruction of farmlands and desertification, are devastating. This study, therefore focused on the processes involved in producing smokeless coal briquettes suitable for use in brick factories, foundries, and laundry and bakery industries and as substitute for fuel wood in domestic cooking to reduce household dependence on firewood, kerosene and liquid petroleum fuels, which are not only very expensive, but also sometimes very scarce. 


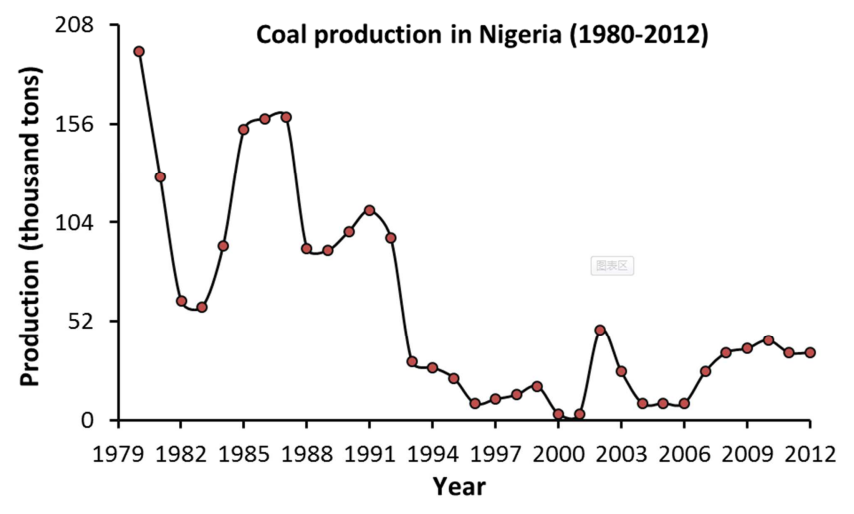

Figure 1. Coal production in Nigeria (International Energy Statistics, 2015).

Table 1. Coal reserves and production potential in Nigeria.

\begin{tabular}{|c|c|c|}
\hline \multicolumn{3}{|c|}{ Coal Reserves in Nigeria } \\
\hline 1 & Proven coal reserves & About 639 million metric tones \\
\hline 2 & Inferred reserves & 2.75 billion metric tonnes \\
\hline \multicolumn{3}{|c|}{ Coal Production Potential in Nigeria } \\
\hline 1 & Underground potential & 200,000 to 600,000 tonnes per year \\
\hline 2 & Surface production potential & $\begin{array}{l}400,000 \text { to } 800,000 \text { tonnes per year } \\
\text { (World Bank, 1983) }\end{array}$ \\
\hline \multicolumn{2}{|c|}{ (c) Coal Fields in Nigeria } & Location \\
\hline 1 & 22 Coal fields & Spread to over 13 States \\
\hline 2 & $\begin{array}{l}\text { Consist of approximately: } \\
49 \% \text { sub-bituminous coal } \\
39 \% \text { bituminous coal } \\
\text { And } 12 \% \text { Lignite coal }\end{array}$ & \\
\hline
\end{tabular}

Source: Nigerian Coal Corporation (nd) [7].

Table 2. Chemical characteristics of air dried Nigerian coal.

\begin{tabular}{|c|c|c|c|}
\hline \multicolumn{4}{|c|}{ Chemical Characteristic of Air-dried Nigerian Coal } \\
\hline & Characteristic & Sub-bituminous Coal & Lignite \\
\hline 1 & Caloric Value, $\mathrm{MJ} / \mathrm{kg}$ & $22.3-28.8$ & $22.9-23.4$ \\
\hline 2 & Moisture content, \% & $2.9-11.1$ & $8.1-12.5$ \\
\hline 3 & Ash content, $\%$ & $3.9-26.0$ & $7.8-10.8$ \\
\hline 4 & Volatile matters, $\%$ & $32.5-41.8$ & $38.9-42.7$ \\
\hline 5 & Fixed carbon, $\%$ & $38.6-46.3$ & $37.8-41.4$ \\
\hline
\end{tabular}

Source: Enibe (1998) [8].

\section{Research Methodology and Materials Used for the Study}

This study highlighted on the reserves, production and utilization potential of the Nigerian coal, processes involved in producing smokeless coal briquette fuel - coal drying, screening, crushing and carbonization to remove obnoxious volatile matters - the production sequence for coal briquetting. The sub-bituminous coal sample used for this study was obtained from Onyeama Mine in Enugu. The briquetting press developed at the Energy Research Center, University of Nigeria Nsukka, was employed for producing the sample briquettes used for evaluating the characteristics (bulk density, porosity index and handling durability etc.) of the briquettes produced in this study. The briquettes were dried using solar dryer developed at the National Centre for Energy Research and Development. The calorific values of the briquettes were determined using an oxygen bomb calorimeter model
XRY-1A. The MB35 Halogen Ohaus moisture analyser was used to determine the moisture contents of the briquettes. The performance of the briquettes (ignition time and burning rate) was carried out by conducting a simple water boiling test using a briquette stove also developed at the National Centre for Energy Research and Development.

\section{Utilization Potential of the Nigerian Coal}

Nigerian coal is environment-friendly due to its low sulphur and ash contents [8], has high calorific values of about 22.3 $\mathrm{MJ} / \mathrm{kg}$ to $28.4 \mathrm{MJ} / \mathrm{kg}$ [9] and therefore has wider areas of applications. The potential areas where coal is used as source of fuel include cement production, brick factories, foundries, and laundry and bakery industries. Other areas of potential uses are as the important raw material base in tyre and battery manufacture, substitute for fuel wood in domestic cooking. In metallurgical industry, Nigerian coal is suitable in producing coke of acceptable strength and character for the steel plants. Up to 200,000 metric tons of Nigerian coal will be required annually when Ajaokuta Steel Plant goes into full production [7]. Okpara and Onyeama Coal in Enugu State have the potentials of providing sources of future coal supply to the steel sector. In power generation, Nigerian coals are suitable as energy fuel for power generation for the abandoned Oij Power Station in Enugu State and other proposed power stations at Kogi, Benue, Anambra and Delta States. With the current deregulation of power generation in the country which was facilitated by the lack of sufficient power generating capacity by PHCN is a fertile ground for the Independent Power Producers. Also coal and its derivatives, smokeless coal briquettes, have been demonstrated as the cheapest, safest and therefore most suitable substitute to fuel wood. About 2 million metric tonnes of coal/briquettes equivalent are required annually to substitute fuel wood utilization. More than 20 carbonization/briquetting plant of 100,000 tons per annual capacity is required to be sited within Okaba, Ogboyoga, Oba/Nnewi, Gombe/Bauchi and Azagba/Ogwashi coal/lignite fields in Nigeria [7]. These plants are yet to be accomplished.

\section{Coal Briquetting Processes}

Coal is often described as a "dirty" fuel emitting smoke that is offensive and containing constituents that are harmful to human health. But with suitable briquetting processes and carbonizing when necessary, coal can be put into a relatively clean, compact, and stable form for uses in the domestic, commercial and industrial sectors. Coal briquetting has a long history. In the late 1800 s relatively worthless fine coal or slack was compressed to form a "patent fuel" or briquette [10]. Coal briquetting has been researched worldwide in places like Germany, USSR, Korea, India, and the United States [11]. Reasons for the extensive research are as follows: (i) All coals are not alike, and often research has been aimed at developing 
an" improved briquetting process for a particular coal. Briquetting can be done with or without an additive (binder) to help in agglomerating and giving cohesive strength to the briquette. (ii) To obtain suitable binders, as well as processes by which briquetting can be performed with or without a binder. (iii) To improve the properties of the briquettes, such as maintaining ignitability while keeping volatile matter low as well as reducing smoke and sulfur emissions upon burning [10]. In coal briquetting, a set of parameters such as temperature, pressure, pressing time, pretreatment, etc can be varied to produce unique briquetting processes. Also, it is very essential that the Run-Off-Mine (ROM) coal is subjected to cleaning and preparation processes [12], which include sorting out and screening of different sizes of coal pieces, removal of impurities such as sulphur, dirt, and mud etc, before dispatch for briquetting. The processes involved in producing "smokeless" fuel briquettes are closely tied to the nature of the feed coal [13] and such processes are discussed as follows:

(i) Coal drying: Methods used in coal drying are direct drying (a flash dryer using hot gas) and indirect drying (a disc dryer using steam heat). This stage is very crucial as moisture content has critical impact on the strength of briquettes. Excess moisture physically militates again development of the maximum contact area that would otherwise be established at a particular pressure. In addition to drying the coal to the appropriate moisture content, it is essential to ensure that moisture is uniformly distributed; and in commercial operations, coal leaving the dryer should be very slowly cooled before dispatch to the briquette press.

(ii) Crushing: This can be done before or after screening. It is generally essential to crush the coal to $<4 \mathrm{~mm}$, with $60-65 \%$ $<1 \mathrm{~mm}$ to facilitate close compaction of coal particles during compression [14]. Crushing coal to this particle size results in a stronger briquette and better ignition properties. The equipment required for crushing include rotary crusher, double roller crusher and hammer mills etc.

(iii) Binders: Coal briquetting can be performed with or without binder. Briquetting without prior addition of binders are required to ensure that the briquette has adequate strength to withstand normal handling. Briquetting is usually conducted at temperature $\left(35-65^{\circ} \mathrm{C}\right)$ at which advantage can be taken of the enhanced plasticity of small particles of and as bulk of binderless lignite briquettes is used for residential heating, the preferred press is Exter extrusion press [14]. In the modern version of this equipment, coal is compacted under approximately $1400 \mathrm{~kg} / \mathrm{cm}^{2}$ by reciprocating ram that pushes it into, and through, a ventrui type channel by repeated forward strokes and simultaneously admits additional coal during each return stroke. Although the high pressures required for satisfactory compaction make production of binderless fuel briquettes from more mature coals uneconomical, smaller quantities are produced for other purposes such as preparation of shaped activated carbon. This operation extends to lignite briquetting by using much more finely comminuted coal - commonly $100 \%<75 \mu \mathrm{m}$ and pressure on the order of $2100-2800 \mathrm{~kg} / \mathrm{cm}^{2}$, requires special mold designs and fairly complex mold-charging cycles [14].
Briquetting coal with a binder, the production sequence can be represented in Figure 2 as follows:

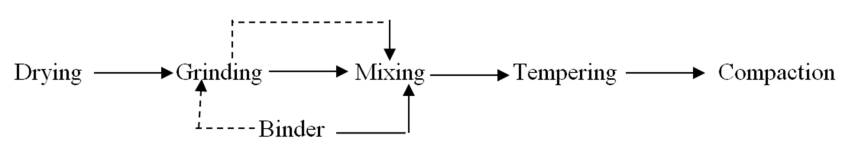

Figure 2. Production sequence for coal briquetting.

The broken lines indicate alternative sequences. Also close attention must be given to the quality of the binder and the manner of introducing into the coal and the overall process is more flexible than briquetting without binder. In most cases the coal is dried to $<4 \%$ moisture, which experience has shown to minimize binder requirements, and crushed to $<1 \mathrm{~mm}$ (with $75-80 \%<0.5 \mathrm{~mm}$ ) [14]. After addition of a binder, the mixture is homogenized by tempering it in a pug where it is heated to $95-100^{\circ} \mathrm{Cby}$ injection of superheated steam and agitated by rotating paddles. And before dispatch to the presses, it is cooled to a few degrees above the softening point of the binder in order to endow it with appropriate plasticity for compaction. The binder is usually a pitch (crushed to $65-95 \%<0.5 \mathrm{~mm}$ ) or a bitumen, and is either introduced into coarse coal, ie between coal drying and grinding or added after grinding stage. Alternatively, it is melted and sprayed into the coal. Bitumen is always applied in liquid form. The binder proportion depends upon the nature of the coal and ranges from 5 to $8 \mathrm{wt} . \%$ in the case of pitch or from 8 to $10 \mathrm{wt}$ \% if bitumen is used. Other binder types include coke oven pitch, petroleum asphalt, and ammonium lignosulphorate, starch and molasses and addition rate is 5 to $15 \%$ by weight $[10]$.

(iv) Devolatilizing: This is only applicable to low- rank high-volatile coals. The equipment used is a retort or a beehive type coke oven. This involves driving off excess gas or volatile matter through carbonization process prior to briquetting in order to produce a "smokeless" fuel.

(v) Sulphur removal from coal: The most objectionable impurities in coal is sulphur. Organically bound sulphur in coal constitutes about $70 \%$ of sulphur in coal and this cannot be removed by physical sorting, rather by chemical cleaning processes [12]. Several steps can be taken to remove sulfur to make the final smokeless coal lump or briquette clean from sulphur oxide emissions. Washing coal with water prior to pyrolysis is a simple, inexpensive, and effective step. High sulphur coals are washed and chemically treated for sulphur removal. Water soluble sulphate and pyritic are removed by washing the coal. The sulphur content of coal can also be reduced by carbonization processes by converting it to hydrogen sulphide gas.

(vi) Coal Carbonization: Burning raw or untreated briquetted coal produces emissions that can have serious health effects. It releases volatile organic matter, sulphur compounds, nitrogen oxides, particulates, and trace elements. Each of these has potential adverse effects on human health. Carbonizing coal to produce a soft smokeless coke can significantly reduce the adverse health effects of burning raw coal or untreated coal briquettes. Carbonization describes the 
process for producing fuels - solid, liquid and gaseous - from coal and other carbonaceous materials such as biomass and organic wastes, by heating them in an oxygen-deficient atmosphere [15]. During the heating the volatile content of coal is reduced, and gases and tars containing some other harmful constituents are given off. The result is a product high in fixed carbon, which can burn with little or no smoke and emissions not worse than the present practice of burning coal and firewood. Carbonization can be performed before or after briquetting - or even without briquetting. One of the important aspects of coal carbonization is that many of the potentially harmful constituents of coal are removed. A certain level of volatiles is left in the soft coke (appx. 1\% to 20\%) to promote its easy ignition, but this level is deemed safe and does not allow the fuel to smoke significantly [14]. Particulates are also considerably reduced by the process of carbonization. Carbonization is only needed for coals below the rank of anthracite, that is, bituminous, sub-bituminous, and lignite coals. Anthracite is sufficiently low in volatile and ash contents and high in fixed carbon that carbonization is unnecessary for a, smokeless fuel.

Carbonization processes can be classified into three based on temperature range: (i) Low Temperature Carbonization (LTC) $\left(450-700^{\circ} \mathrm{C}\right)$ is used on small scale to produce smokeless solid fuel, and by-product tars as essential feedstocks to chemical industry or refined to synthetic motor gasoline, heating oil, and lubricants [16]. Preferred coals - As a rule, are lignite or sub-bituminous and high-volatile bituminous coals, when pyrolyzed at temperatures between 600 and $800^{\circ} \mathrm{C}$ furnish porous chars or so-called semicokes [14]. LTC Equipment: Vertical and Horizontal retorts - with process heats supplied directly by circulating hot combustion gas through the charge or indirectly by passing it through flues between contiguous retorts - were used for batch as well as continuous processing. (ii) Medium Temperature Carbonization (MTC): If LT carbonization is extended into the $700-900^{\circ} \mathrm{C}$ range, it is termed medium temperature processes. This reflects the pronounced physical changes that coal undergoes between 600 and $800^{\circ} \mathrm{C}$. (iii) High Temperature Carbonization (HTC): HT carbonization is normally carried out at or above $900^{\circ} \mathrm{C}$. If coal is carbonized at temperatures above $650-700^{\circ} \mathrm{C}$, LT chars will become less reactive through devolatilization and loss of porosity [14]. At this point, the chars tend to lose the properties that make them useful domestic and industrial boiler fuels (difficult to ignite). In practice, HTC is therefore limited to the production of metallurgical cokes, which acquire much of their industrial utility through processing at high temperatures.

\section{Coal Briquetting Press}

Different types of coal briquetting presses are already in existence ranging from simple to complex ones and they include roll types and hydraulic piston press, pellet press, screw-press and extruder types etc. These machines are either very expensive or not readily available for local production of briquettes in Nigeria. The mechanical construction of the machines determines such important characteristics as reliability, ease of maintenance and cost of operation. Depending on the configuration of the mould installed in the press, briquettes are produced in different shapes such as: (i) pillow shape (most common), (ii) circular, polygonal, or irregular in cross-section; (iii) they may be solid or concentrically perforated to form a hollow cylinder or polygon.

Figures 3 (a) and (b) show a briquetting press designed and fabricated at the Energy Research Center, University of Nigeria Nsukka, indicating different parts of the press. The press was designed to be manually operated to circumvent power supply issues, for it to be used in a remote location and to minimize cost for the local users. However, it can still be automated to increase production rate. It uses two vertically mounted $200 \mathrm{kN}$ capacity hydraulic presses to generate its maximum compaction pressure of $160 \mathrm{~N} / \mathrm{m}^{2}$ and has twelve cavities of $70 \mathrm{~mm} \times 100 \mathrm{~mm}$ cross-sectional area, where the coal-binder mixture is to be loaded for compaction. The high pressure ram of the press is used in compressing the briquettes and the ejector ram is for ejecting the compacted briquettes.

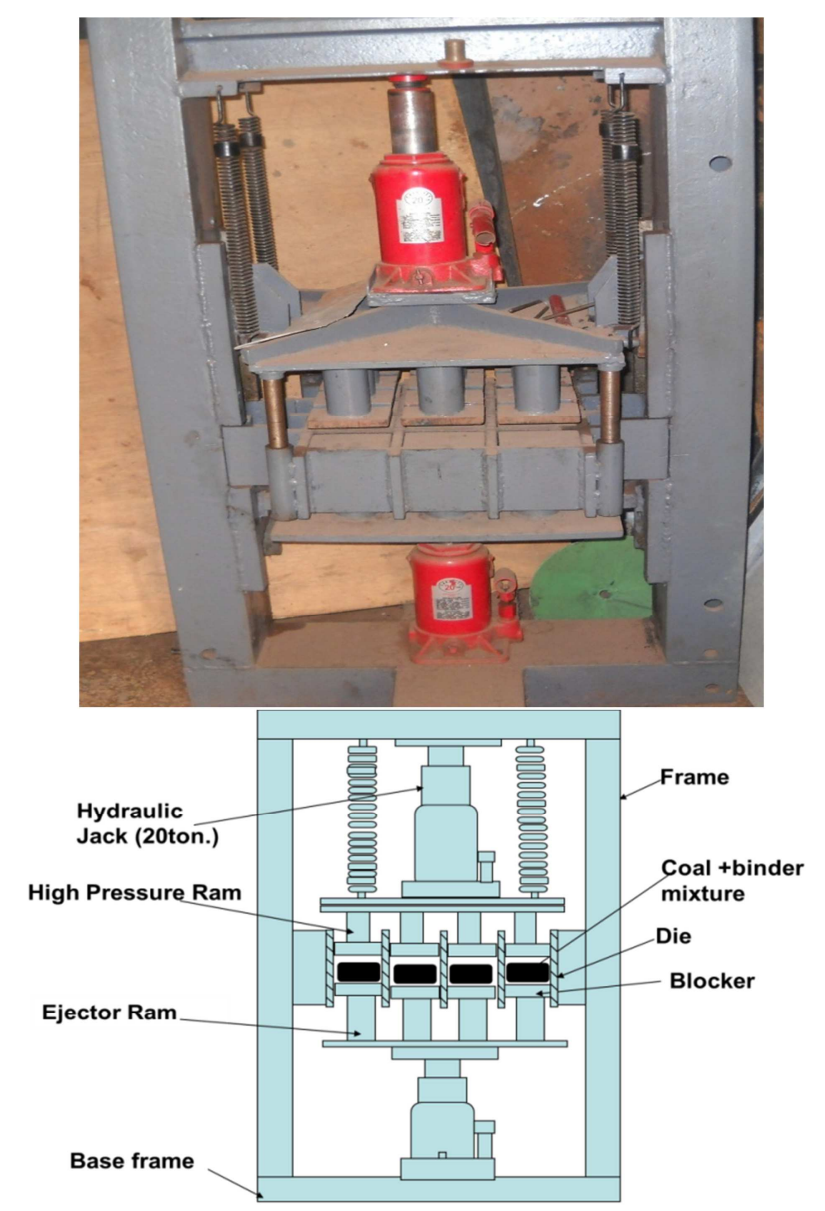

Figures 3. (a) Pictorial view of the briquetting press; (b) Sectional view of the briquetting press.

The press is designed to handle maximum load up to $7 \mathrm{~kg}$ of coal-binder or coal-biomass-binder mixtures in a single batch operation and can produce more than 2.8 tonnes of briquettes per day. The frame structure of the press was designed with 
metal steel to provide the required rigidity to withstand high pressure, ensure durability and efficient performance.

\section{Performance Evaluation of the Samples Briquettes Produced by the Press}

A sub-bituminous coal sample obtained from the Okpara mine in Enugu was used in producing the briquettes. The coal sample struck into small chunks was washed in a container filled with water to remove impurities and then sun-dried for three days to reduce moisture content. The washed sample was pulverized with a grinding machine and sieved to particle sizes of not more than $1 \mathrm{~mm}$ and then carbonized at the temperature of about $550^{\circ} \mathrm{C}$. The pulverized coal-binder (cassava starch) mixtures were compacted at constant pressure of $9 \mathrm{~N} / \mathrm{mm}^{2}$ and allowed to stay for 5 minutes (dwell time) before ejecting the compacted briquettes. The starch-binder is normally used in briquetting industries. The briquettes produced with starch-binder ignite easily and they burn with less ash deposits compared to that produced with asphalt as binder. The three briquettes samples B, C and D shown in Figure 4 were produced with the briquetting press in Figure 3. The briquettes were dried using solar dryer developed at the National Centre for Energy Research and Development. The calorific values of the briquettes were determined using an oxygen bomb calorimeter model XRY-1A. The MB35 Halogen Ohaus moisture analyser was used to determine the moisture contents of the briquettes.
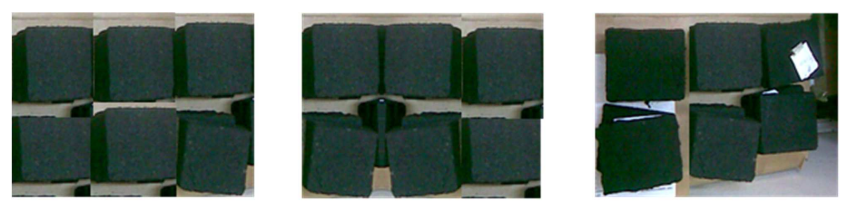

Figure 4. Sample B briquettes Sample C briquettes Sample D briquettes

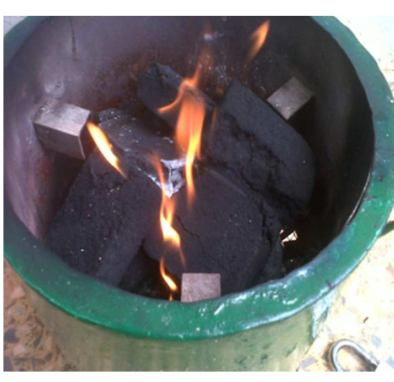

(a)

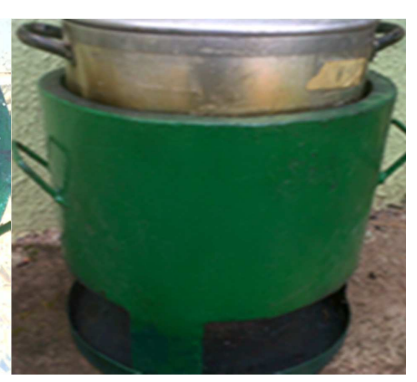

(b)
The bulk density of the briquettes was determined from ratio of the mass and volume of each sample of the produced briquettes. The porosities of the briquettes were determined from the ratio of the mass of water absorbed by the sample briquettes when immersed in water for 25 minutes to the mass of each sample of the briquettes immersed in the water [17]. The handling durability (shattering index) of the briquettes was determined from ratio of the weight of briquettes still remaining in the sieve after dropping each sample from a height of $2 \mathrm{~m}$ on a concrete floor to the weight of the briquettes before the dropping [18]. Also, the ignition time for the sample briquettes was determined as the time it took each sample briquettes to catch fire when it was lit at its edge and this was repeated three times for each sample and the average time was taken as the ignition time. Figure 5 (a) shows the burning briquettes.

The performance of the briquettes was also carried out by conducting a simple water boiling test using a briquette stove shown in Figure 5 (b) also developed at the National Centre for Energy Research and Development. In this test, the stove was loaded with four pieces of sample B briquette used for heating 2.5 liters of water to boiling and $3 \mathrm{~mL}$ of kerosene were used to ignite the briquettes. The weight of the burnt briquette was obtained by calculating the difference in the initial weight of the stove loaded with the briquettes and the final weight when the water started boiling and the pot with the boiling water removed from the stove. The burning rate was determined. The processes were repeated for sample $\mathrm{C}$ and $\mathrm{D}$ briquettes.

\section{Results and Discussion}

The produced briquette samples B, C and D weighed average $198.5 \mathrm{~g}, 159.67 \mathrm{~g}$ and $149.45 \mathrm{~g}$ respectively after five days drying using a passive solar dryer. The briquettes exhibited very insignificant linear expansions while ejecting them from the mould. Table 3 shows the proximate analysis for the pulverized raw coal (sample A) and the three sample briquettes produced with the press. It indicates that the calorific values, ash contents and fixed carbons of the briquettes tend to decrease with an increase in starch-binder concentrations, while the moisture contents and volatiles increased with an increase in the starch-binder concentrations. The higher calorific value for sample B briquette indicates that they could release more heat during combustion than the briquettes $\mathrm{C}$ and $\mathrm{D}$. The lower ash content of sample $\mathrm{D}$ indicates that it contains less noncombustible materials than briquettes B and C. The higher ash content of sample B could retard the burning rate of the briquette.

Figure 5. (a) Burning briquettes in the stove and (b) briquette stove used for the water boiling test.

Table 3. Characteristics of the pulverized raw coal (sample A) and produced briquettes.

\begin{tabular}{|c|c|c|c|c|c|}
\hline Briquette Sample & Calorific Value(MJ/kg) & \%Moisture Content & $\%$ Volatiles & \%Ash Content & \% Fixed Carbon \\
\hline $\mathrm{A}$ & 27.46 & 7.20 & 36.14 & 18.53 & 38.13 \\
\hline B & 26.36 & 8.11 & 37.83 & 16.95 & 37.11 \\
\hline $\mathrm{C}$ & 25.23 & 9.52 & 39.12 & 15.03 & 36.33 \\
\hline $\mathrm{D}$ & 24.82 & 11.23 & 40.84 & 13.37 & 34.56 \\
\hline
\end{tabular}


Table 4. Performance analysis of the produced sample briquettes.

\begin{tabular}{llll}
\hline & B - Coal (95\%) + Binder (5\%) & C- Coal (90\%) + Binder (10\%) & D-Coal (85\%) + Binder (15\%) \\
\hline Bulk density $\left(\mathrm{g} / \mathrm{cm}^{3}\right)$ & 1.03 & 1.01 & 0.91 \\
Porosity index & 0.24 & 0.19 & 0.14 \\
Handling durability & 0.061 & 0.052 & 0.043 \\
Ignition time ( $\mathrm{min})$ & 1.31 & 1.56 & 2.18 \\
Burning rate (g/min) & 2.65 & 2.30 & 1.91 \\
Smoke & $\begin{array}{l}\text { Burnt with little white smoke on starting } \\
\text { the fire and vanished when fully ignited. }\end{array}$ & $\begin{array}{l}\text { Burnt with little white smoke on starting } \\
\text { the fire and vanished when fully ignited. }\end{array}$ & $\begin{array}{l}\text { Burnt with little white smoke on starting } \\
\text { the fire and vanished when fully ignited. }\end{array}$ \\
Odour & $\begin{array}{l}\text { Burnt with no odour, except on starting } \\
\text { the fire. }\end{array}$ & $\begin{array}{l}\text { Burnt with no odour, except on starting } \\
\text { the fire. }\end{array}$ & $\begin{array}{l}\text { Burnt with no odour, except on starting the } \\
\text { fire. }\end{array}$ \\
\hline
\end{tabular}

Table 4 indicates that the bulk density and porosity index of the briquettes decreased with an increase in the binder concentration. The ignition time increased with an increase in the binder concentration and this could be due to decrease in the porosity of the briquette. The lower porosity index exhibited by sample $\mathrm{D}$ could reduce the heat and mass transfer rate during combustion due to a decrease in voids in the briquette matrix as a result of the increase in the binder concentration. The briquette D also exhibited best handling quality due to its lower shattering index when dropped from a height of $2 \mathrm{~m}$ on a cemented concrete floor due to its higher binder concentration. The briquette $\mathrm{B}$ has a higher burning rate due to its higher volatile content and porosity index and lower moisture content.

\section{Conclusion}

Coal was the oldest commercial fuel to be exploited by Nigeria, but later neglected due oil boom and other factors. Through coal briquetting, efforts are being made to increase the country's level of coal utilization to help reduce over dependence on crude oil and to stem the loss of forests to domestic fuelwood harvesting. Coal briquetting involves processing and compacting pulverized coal mixed with or without binder in briquetting press to produce solid fuels. Carbonizing coal to produce smokeless briquettes fuel reduces the volatile matters that adversely affect health from burning raw coal or untreated coal briquettes. The calorific values and fixed carbon content of the produced briquettes decreased with an increase in the starch-binder concentrations. The moisture and volatile contents of the briquettes tend to increase with an increase in the starch-binder concentration, but the ash content decreased with an increase in starch-binder concentration. The handling quality of the briquettes increased with an increase in the starch-binder concentration, but this lowers the burning rate and increased the ignition time due to decrease in the calorific values and porosity index of the briquettes.

\section{References}

[1] Nigeria-Coal and Lignite-OnlineNigeria.com, (2006). www.onlinenigeria.com/aboutus.asp.

[2] Oyeyinka, Management of Technological Change in Africa:
The Coal Industry in Nigeria International Development Research Centre, pp. 3-29, (2004).

[3] Dayo, F. B., Clean Energy Investment in Nigeria: The domestic context. Published by the International Institute for Sustainable Development, 161 Portage Avenue East, 6th Floor Winnipeg, Manitoba Canada R3B 0Y4, pp. 24 - 26, 2008.

[4] Pallavi, S., Nigeria Coal Production 1980-2012. International Energy Statistics, 2015.

[5] EIA, Country Analysis Brief - Nigeria, U. S. Energy Information Administration, 2005. www.eia.gov/emeu/ecbs/nigeria.html.

[6] ICEED, Improved woodstoves Workshop and Exhibition. International Centre for Energy, Environment and Development, 2007. http://www.iceednigeria.org/project.

[7] Nigerian Coal Corporation (nd). Coal Reserves and Production Potential in Nigeria. Nigerian Coal Corporation, Okpara Avenue, Enugu, Nigeria.

[8] Local Sourcing of Raw Materials: Solid Mineral Deposits in Nigeria Profile (1999): Nigeria Investment Commission, Maitama District Abuja Nigeria. www.nipc-nigeria.org/solidmin.htm

[9] Enibe, S. O. Power Plant Engineering Lecture Notes, 1998. Department of Mechanical Engineering, University of Nigeria, Nsukka. Unpublished.

[10] Walters, A. D. (nd). Coal Preparation. www.ilo.org/safework_bookshelf/english? content\&nd.

[11] Komarek, K.R. The Briquetting Process and Compacting Process. Inc. 548 Clayton Ct. Wood Dale, IL, 60191, USA. 2009. http://www.komarek.com/briquette-process.html

[12] Rao, S. and Parulekar, B., Energy Technology Nonconventional, Renewable and Conventional. Khanna Publishers, 2-B Nath Market, Nai Sarak, Delhi - 110006, pp.742- 744. 2004.

[13] Krug and Nauendorf "Briquetting of brown coal Volume 1, section on Drying, VEB Deutscher Verlag fur Grundstoffindustrie, Leipzig, 1984, 1st Edition.

[14] Barkowitz, N., An Introduction to Coal Technology. Second edition. Academic Press INC. 525 B Street, Suite 1900, San Diego, California 92101 - 4495, pp. 205-209, 1994.

[15] Skodras, G. and Amarantos, P., Overview of Low Temperature Carbonisation. Center for Research and Technology Hellas Institute for Solid Fuels Technology and Applications, 2004.

[16] King, J., GLow-Temperature Carbonisation. 1st World Petroleum Congress, London, UK, 2003. 
[17] Ikelle I. I. and Mbam. J. The Study of Briquettes Produced With Bitumen, CaSO4 and Starch as Binders. American Journal of Engineering Research (AJER) Volume-03, Issue-06, pp-221-226, 2014.
[18] Davies R. M. and Abolude D. S., Mechanical Handling Characteristics of Briquettes Produced from Water Hyacinth and Plantain Peel as Binder Journal of Scientific Research \& Reports 2(1): 93-102, 2013. 